\title{
Pedagogical reflection as a professional competence in conditions of lifelong pedagogical education
}

\author{
N.V. Gorbunova ${ }^{1 *}$, N.A. Gluzman ${ }^{2}$, and I.V. Osadchaya ${ }^{3}$ \\ ${ }^{1}$ V.I. Vernadsky Crimean Federal University, Simferopol, Russia \\ ${ }^{2}$ V.I. Vernadsky Crimean Federal University, Simferopol, Russia \\ ${ }^{3}$ V.I. Vernadsky Crimean Federal University, Simferopol, Russia
}

\begin{abstract}
In the article, pedagogical reflection is considered as a professional competence, its essence, stages and mechanisms for reflexing pedagogical activity are presented. The reflection phenomenon is revealed in an integrative context, the specifics of its revealing in the professional experience of the teacher is described. The role of reflexive thinking in professional pedagogical activity is justified. The conditions for the development of professional reflection of the teacher were highlighted. The most important among them are: updating the teacher's reflexivity; specially organized reflexive activity of the teacher; the presence of a reflexive environment; enhancing the interpersonal relationships of participants in reflexive activities; development of professional reflection using educational programs. The model of personal reflexive support of the specialist is analyzed and necessity of its application is justified. The main goal of reflexive support for the development of the teacher's personality should be the creation of favorable conditions for the formation of a mature professional identity. Continuing pedagogical education represents the constant creative development and improvement of each person throughout life by means of the interaction of all the knowledge obtained at different life stages and stages of learning.
\end{abstract}

\section{A problem statement}

Nowadays human capital is becoming more and more valuable, despite the fact that there is a sharp conflict between a centrist, personal-oriented approach and a constantly developing and widespread technological approach that is seen in all spheres of life, including education. Rapidly developing technologies and digitalization, on the one hand, facilitates our life and professional activities of representatives of many professions, also contributing to the emergence of new professions, professions included in the top-100, professions of the future. On the other hand, the digitalization and technology in the nearest future will supplant a number of professions and specialists who can be replaced with the machines.

\footnotetext{
*Corresponding author: prof-ped.gpa@mail.ru
} 
The issues of digitalization, technologization, artificial intelligence, and at the same time, human capital are very acute in the modern world. A competency approach can be combining, as the integral indicator of the quality of modern education is a competence, characterizing the person's ability to mobilize the knowledge and experience gained in a particular situation. The competency approach is not new in education, since the orientation towards the mastery of knowledge, generalized ways of activity also existed in domestic science and was one of the leading ones. The purpose of implementing a competent approach in high education is the formation of a competent specialist. At the same time, the task of compensating the forces and opportunities comes to the fore[1,2].

As the domestic scientists emphasize (V.N. Belkina, I.I. Revyakina), "modern higher teacher training is developing in line with a competent approach, the essence of which is the formation of a number of integrative professional skills of the graduates designed to ensure the successful teacher's solution of various tasks of teaching, education, development of a growing person. Such skills are called the professional competencies. Some of them can be common cultural, common pedagogical and special ones. Such competencies include pedagogical reflection, which simultaneously acts as a mechanism for the formation and improvement of a professional" [3].

In pedagogical practice, reflection is considered as an intellectual and emotional activity, during which the teacher realizes his teaching experience in order to obtain a holistic idea of the optimal choice of ways and methods of work, to obtain qualitative results. According to T.M. Riedel, reflection should be interpreted as a process and result of participants fixing its state of development, self-development and their causes; as one of the mechanisms for self-regulation of the teacher's professional activities and an incentive for continuing professional development [4].

Reflection contributes to the professional and personal teacher growth. Professional growth is aimed at achieving high qualifications, development of professional skills, optimal choice of methods and means of training, achieving high results in professional activities, which leads to advanced training. Personal growth involves the development of such professionally significant qualities as analytical skills, critical thinking, motivation, creativity, a value system; it relates to self-improvement and self-development. Pedagogical reflection plays an important role in the professional development of the teacher. Using the reflection, the teacher analyzes the gained experience, draws conclusions and makes plans for the future. Reflection helps the teacher to show great flexibility in planning classes taking into account the real communicative needs and psychological characteristics of students, ensures the implementation of a personal-oriented approach to teaching.

\subsection{The objective of the work}

Human capital is one of the mega-significant values of modern society. This is relevant for any sphere of human activity, but the principle of human centrism in the field of education is especially urgent. In the modern world, educational trends and human values are rapidly changing. And just an important task of the teacher is search of balance, effective ways and ways of formation not only common cultural, common professional, professional, universal, additional universal competences, but also that isn't less important, human values, ethical standards and rules, laws of human communication.

At the present stage of the development of society, competent approach comes to the fore especially in teacher training. It allows the future newcomers to master the largest possible set of necessary competencies that ensure their demand on the labor market, a high level of competitiveness, personal and professional development, and career growth. 
Along with the competent approach, the principle of long-life education, i.e. the transition from "education for a whole life" to "long-life education," is updated in domestic pedagogy [5].

The humanistic paradigm is widespread today simultaneously with the technological and digital ones. At the beginning of the 21 st century, the UNESCO Institute for Education Planning presented the topical scientific issues through the key prism of areas: systems and models of professional development of teachers; factors affecting the effective professional development; the impact of the professional development on teachers, students and the success of educational reforms; stages and content of professional development of teachers; a culture of support for the professional development of teachers[6, 7, 8].

The inability of traditional pedagogical practices to meet the needs of a rapidly changing post-industrial society, which is becoming a global environment of intercultural interaction, is becoming evident. Analytical studies of international and national organizations show that teachers lack competencies for professional activities in the context of the globalization of education, which requires a revision of the requirements for the professional development, pedagogical reflection of pedagogical staff:

- teachers are the practical masters who have a deep understanding of the content of the taught subjects and they successfully involve students in their study by demonstrating the relationship of content with everyday practical life;

- teachers are thinkers who are able to solve problems of different levels of complexity, understanding their nature; collecting, analyzing, systematizing information from different sources; offer a viable solution to the problem; they observe their pedagogical activities; use new strategies for searching for personal approaches to each;

- teachers are culturally developed professionals who admit, value and respect the ethnic and cultural diversity of students;

- teachers are familiar with global transformations in the world; they understand international problems of a global nature; monitor key events in the world and help students understand them in interaction;

- teachers are well-educated individuals; who are well acquainted with modern trends in culture, art, music, literature;

- teachers are members of a single team, value and respect the diversity of thoughts; work effectively with representatives of other cultures, colleagues with different levels of professional experience; constantly enhance the professional skills, participate in trainings, mentoring;

- teachers are users of information, communication and media technologies, possess IT and communication technologies;

- teachers are responsible and moral citizens (Devlin-Foltz B.) $[9,10]$.

\section{Results of the research}

The phenomenon of "a reflection" is actively studied by scientists in several aspects:

- as a mechanism of awareness of pedagogical activities;

- as a way of strengthening the pedagogical influence on the student;

- as a resource of the teacher's mastery of pedagogical skills.

As I.A. Zyazyun considered, the teacher's creativity is impossible without reflection. The search for the answer to the question "What contributes to the development of reflection" was carried out by domestic and foreign scientists. Thus, G. Jibbs proposed the method of "structured briefing", the essence of which is implemented in the description, feelings, assessment, analysis process, conclusions and action plan.

Professional reflection is a specific type of teacher's activity, the basis of which is the process of improvement through the ability to introspect in order to understand the goals 
and structure of his activities and the means of optimizing it, self-realizing as the subject of his own activities: own features, abilities, assessing students and parents' perception.

The teachers of the Humanities and Education Science Academy during the students' training course 44.03.01 "Pedagogical Education" Training Profile "Primary school teacher training" were invited to observe indirectly the activities of students during the course of pedagogical practice, identify the difficulties and typical problems of student trainees and, having shown a reflexive position, help them solve certain problem situations. Observations showed that a situation was quite typical when student trainees did not know how to assemble a class, how to organize students, what to do with them, there was insufficient methodological literacy of students. Teachers saw trainees fear, especially fear of children. The trainees often showed uncertainty in themselves and their knowledge. In such situations, the educator should come to the aid of a student-practitioner, demonstrating his reflexive position. The teacher, as a rule, reassures the trainee, cheers him, convincing him that this task is not very difficult and it can be completed by any student. Further, the teacher continues to strengthen the trainee's confidence, in case of the failure offering his help and a tip. He or she gives a piece of advice, as well as understands the problem together. The teacher's reflexive position in such situation should be unobtrusive, but motivated by success, the removal of emotional experiences and the translation of the student's reflexive attitudes into a positive projection. The teacher can offer different options for solving situations. The orientation towards success, ability to master the motivation of achievement is particularly important in the context of solving certain situations (D. Atkinson, H. Hekhausen) [11, 12].

The ability to rethink one's own professional and personal experience is formed at the subject of activity gradually and it is differently developed among different people. As one of the main mechanisms of subjective human development, professional reflection provides:

- the subject's ability to reconstruct and analyze the logic of his thought, determine its composition and structure, objectify, implement;

- the search for new knowledge within themselves, thereby ensuring self-knowledge;

- analysis of thinking and control of mental strategies;

- differentiation of phenomena, the causes of which lie in the middle of the situation and beyond the subject.

During the experimental work, the presence of professional interests, the formation of personal qualities, professional competencies, the presence of professional values, the ideal qualities of a professional; motivation for professional formation, ability to achieve results were also checked.

The results of the ascertaining experiment are shown in Table 1.

Table 1. Results of the ascertaining experiment in the control and experimental group (in \%).

\begin{tabular}{|l|c|c|}
\hline \multicolumn{1}{|c|}{$\begin{array}{c}\text { Criteria for the development of pedagogical } \\
\text { reflection }\end{array}$} & experimental group & control group \\
\hline the presence of professional interests & 28.7 & 27.9 \\
\hline the formation of personal qualities & 22.6 & 21.2 \\
\hline the formation of professional competencies & 21.4 & 21.6 \\
\hline the presence of professional values & 8.7 & 9.2 \\
\hline the formation of the ideal qualities of a professional & 5.4 & 5.2 \\
\hline motivation for professional formation & 8.4 & 9.3 \\
\hline ability to achieve results & 4.8 & 5.6 \\
\hline
\end{tabular}

As the analysis of the results of the ascertaining experiment shows: most respondents of the experimental and control groups have professional interests $(28.7 \%$ of students of the experimental and $27.9 \%$ of respondents of the control groups); personality formation 
(22.6\% for experimental respondents and $21.2 \%$ for control group students); the formation of professional competencies $(21.4 \%$ of students in the experimental group and $21.6 \%$ of students in the control group). The presence of professional values was found in $8.7 \%$ of students in the experimental group and in $9.2 \%$ of the control group. $8.4 \%$ of the respondents of the experimental group and $9.3 \%$ of the control group students showed motivation for professional formation.

The formation of the ideal qualities of a professional was manifested in $5.4 \%$ of respondents of the experimental and $5.2 \%$ of students of the control group. $4.8 \%$ of experimental respondents and $5.6 \%$ of control group students showed the ability to achieve the result.

At the formative stage of the study, a model of the development of pedagogical reflection was implemented.

The model for the development of pedagogical reflection is:

- alternative, flexible;

- problematic;

- integrative.

The model for the development of pedagogical reflection includes a number of components:

- motivational and stimulating component;

- cognitive and informative component;

- activity and operational component;

- productive and efficient component.

The motivational and stimulating component involved reflection of professional attitude. It was aimed at professional formation, the formation of professional status.

The cognitive and informative component formed creative and cognitive processes, thinking, and professional attitude.

The activity and operational component was aimed at professional activities.

The productive and efficient component was aimed at building professional productivity $[13,14]$.

The control study revealed significant positive changes in all indicators. The comparative results are shown in Table 2.

Table 2. Comparative results of the ascertaining and control experiments in the control and experimental groups $(\%)$.

\begin{tabular}{|c|c|c|c|c|}
\hline \multirow{2}{*}{$\begin{array}{l}\text { Criteria for the development } \\
\text { of pedagogical reflection }\end{array}$} & \multicolumn{2}{|c|}{ experimental group } & \multicolumn{2}{|c|}{ control group } \\
\hline & $\begin{array}{c}\text { ascertaining } \\
\text { experiment }\end{array}$ & $\begin{array}{c}\text { control } \\
\text { experime } \\
\text { nt }\end{array}$ & $\begin{array}{c}\text { ascertaining } \\
\text { experiment }\end{array}$ & $\begin{array}{c}\text { control } \\
\text { experiment }\end{array}$ \\
\hline $\begin{array}{l}\text { the presence of professional } \\
\text { interests }\end{array}$ & 28.7 & 52.4 & 27.9 & 35.6 \\
\hline $\begin{array}{l}\text { the formation of personal } \\
\text { qualities }\end{array}$ & 22.6 & 48.6 & 21.2 & 28.9 \\
\hline $\begin{array}{l}\text { the formation of professional } \\
\text { competencies }\end{array}$ & 21.4 & 43.5 & 21.6 & 26.6 \\
\hline $\begin{array}{l}\text { the presence of professional } \\
\text { values }\end{array}$ & 8.7 & 23.2 & 9.2 & 12.8 \\
\hline $\begin{array}{l}\text { the formation of the ideal } \\
\text { qualities of a professional }\end{array}$ & 5.4 & 14.8 & 5.2 & 6.9 \\
\hline $\begin{array}{l}\text { motivation for professional } \\
\text { formation }\end{array}$ & 8.4 & 24.6 & 9.3 & 11.4 \\
\hline ability to achieve results & 4.8 & 10.2 & 5.6 & 7.2 \\
\hline
\end{tabular}


The analysis of the results shows the significant positive changes occurred in the experimental group. Thus, the presence of professional interests increased from $28.7 \%$ during the ascertaining survey to $52.4 \%$ at the control stage. The formation of personality qualities increased significantly from $22.6 \%$ during the ascertaining research to $48.6 \%$ at the control stage. The number of respondents with the formation of professional competencies increased significantly: from $21.4 \%$ at the ascertaining stage to $43.5 \%$ at the control stage. The presence of professional values of respondents increased from $8.7 \%$ during the ascertaining examination to $23.2 \%$ during the control experiment. The level of formation of the ideal qualities of a skilled specialist increased: from $5.4 \%$ during the ascertaining examination to $14.8 \%$ during a control experiment.

Motivation for professional development increased from $8.4 \%$ in the ascertaining survey to $24.6 \%$ during the control examination. The ability to achieve the result has also increased: from $4.8 \%$ at the ascertaining stage to $10.2 \%$ at the control stage.

The control group also showed positive changes, although less significant. Thus, the presence of professional interests increased from $27.9 \%$ during the ascertaining survey to $35.6 \%$ at the control stage. The formation of personality qualities increased significantly from $21.2 \%$ at the ascertaining examination to $28.9 \%$ at the control stage. The number of respondents with the formation of professional competencies increased significantly: from $21.6 \%$ at the ascertaining stage to $26.6 \%$ at the control stage. The presence of professional values of respondents increased from $9.2 \%$ during the ascertaining examination to $12.8 \%$ during the control experiment. The level of formation of the ideal qualities of a professional increased: from $5.2 \%$ during the ascertaining examination to $6.9 \%$ during the control experiment. Motivation for professional development increased from $9.3 \%$ in the ascertaining survey to $11.4 \%$ in the control survey. The ability to achieve the result has also increased: from $5.6 \%$ at the ascertaining stage to $7.2 \%$ at the control stage.

Similar results are obtained by the other authors. So, Marie Tikha and Alena Hospesova emphasize that to work effectively, the teacher must have professional skills and inclinations, "competence". These authors consider competence in reflection, aimed at the activity of a teacher in the sphere of pedagogy, indispensable for the professional development of teachers. In terms of goals and content, teacher training and working methods, developing conscious self-reflection on one's own thinking with other teachers, can contribute to the teacher's professional development.

According to a number of scientists, teachers of professional programs should use pedagogical approaches that better prepare students with knowledge, values and skills for professional practice. Providing academic content itself may not provide the problemsolving skills needed to practice in a complex world in which practitioners must analyze, evaluate and revise knowledge. The reflexive process becomes the main skill for effective functioning in a diverse and complex practical environment (Lisa McGuire, Kathy Lay) [15].

The obtained results testify to the perspective of the developed model of the development of pedagogical reflection in the process of continuous pedagogical education.

\section{Conclusions}

Thus, in the conditions of life-long education, the pedagogical reflection is considered as an important pedagogical competence. The conditions for the development of teacher's professional reflection are the presence of a reflexive environment; actualization of the teacher's reflexivity; specially organized reflexive activity of the teacher; enhancing the interpersonal relationships of participants in reflexive activities; development of professional reflection by means of educational programs. 
The model of formation of pedagogical reflection combines professional the goals and interests; professional actions; professional achievements and results; professionally relevant qualities; stages of professional career; values of professional activity.

The introduction of a model for the formation of pedagogical reflection ensures an increase in understanding of the process of professionalization as personally significant; awareness of the need for self-activity in professional and life formation; developing of reflexivity in the process of self-identification with the profession.

\section{References}

1. B.J.L. Berry, (ed.), Urbanization and Counterarbanization (1976)

2. P. Hall, and D. Hay, Growth Centres in the European Urban System (1980)

3. V.N. Belkina, I.I. Revyakina, Pedagogical reflection as professional competence, Yaroslavl Pedagogical Bulletin 3, 203-206 (2010)

4. T.M. Riedel, Reflection and a reflexive approach to the process of forming the optimal motivation of students' teachings in the process of studying foreign languages, Electronic resource, Access Mode: www.rusnauka.com/11_NPE_2012/Pedagogica/2_107631.doc.htm

5. J. Friedmann, Regional Development Policy (1966)

6. I.A. Zyazyun, Reflexion of People in Humanitarian Philosophy, Svitlo, 1, 6-9 (1988)

7. J. Gibbs, The evolution of population concentration, Economic Geography, 119-129 (1963)

8. F. Caena, Literature review: quality in teacher's continuing professional development (2011)

9. B. Devlin-Foltz, S. MacIlvaine, Teacher preparation for the global age: the imperative for change, Longview Foundation for Education in World Affairs and international understanding (2008)

10. Marie Ticha \& Alena Hospesova, Qualified Pedagogical Reflection as a Way to Improve Mathematics Education, Journal of Mathematics Teacher Education, 9, 129156 (2006)

11. J.W. Atkinson, Psychology: Biographical bibliographic dictionary (1999)

12. H. Heckhausen, Motivation and Activity, Pedagogy, 1 (1986)

13. N.V. Gorbunova, A.M. Kalimullin, Simulation of the Process of Training the Future Primary School Teachers for Organizing Extracurricular Activities, Elementary Education Online, 4 (2017)

14. N.A. Gluzman, N.V. Gorbunova, Teacher professionalism: success and career (2017)

15. Lisa McGuire, James Madison, Kathy Lay, Pedagogy of Reflective Writing in Professional Education, Journal of the Scholarship of Teaching and Learning, 9(1) (2009) 